\title{
DIREITOS HUMANOS E DIVERSIDADE RELIGIOSA: NOTAS DE PESQUISA
}

\author{
Human rights and religious diversity: notes of research
}

\author{
Mailson Fernandes Cabral de Souza \\ Mestre em Ciências da Religião pela Universidade \\ Católica de Pernambuco (UNICAP). Atualmente é \\ colaborador e membro do Observatório \\ Transdisciplinar das Religiões no Recife. Tem \\ experiência na área de pesquisa em Ciências da \\ Religião e Análise do Discurso de linha francesa, \\ com ênfase em diversidade religiosa, laicidade, \\ liberdade religiosa e direitos humanos. Interessa-se \\ pelo estudo, sob o viés discursivo, das relações \\ entre religião e espaço público no Brasil. \\ Email: mailsoncabral@yahoo.com.br
}

Informações do artigo

Recebido em 05/05/2017

Aceito em 21/08/2017

\begin{abstract}
Resumo
O presente artigo tem por objetivo apresentar um breve itinerário da relação entre direitos humanos e diversidade religiosa no Brasil, a partir do recorte estabelecido na nossa pesquisa de mestrado sobre o discurso político do Comitê Nacional de Respeito à Diversidade Religiosa (CNRDR). Com o propósito de entender como se dá a relação entre religião e espaço público no cenário brasileiro, o discurso do CNRDR é tomado como ponto de observação, sendo apresentados alguns dos seus principais aspectos que foram observados no decorrer da pesquisa. Tendo como marco teórico-metodológico da pesquisa a Análise do Discurso de linha francesa, foi possível perceber, no discursivo do comitê, que a relação entre direitos humanos e diversidade religiosa se dá por meio de uma dinâmica de contradição e de complementaridade, o que trouxe à evidência que o CNRDR não possui um conceito de diversidade religiosa estabelecido. Apesar disso, essa noção, heterogênea e aberta, permite a inserção da religião no âmbito das políticas públicas. Sob esse viés, a diversidade religiosa pode representar um gesto de leitura para a compreensão dos embates ideológicos que acontecem na relação entre religião e política no espaço público brasileiro.

Palavras-chave: Espaço público. Liberdade religiosa. Religião e Discurso.
\end{abstract}

\section{Introdução}

Por um longo tempo, no Brasil, inexistiram políticas públicas voltadas para o combate da intolerância religiosa e para a promoção da liberdade e da diversidade religiosa. Um importante fator que contribuiu para a mudança desse quadro foram os direitos humanos. A princípio, o movimento em sua defesa emergiu na arena pública a partir das lutas sociais contra a ditadura militar, contudo eles só entraram definitivamente para a agenda política nacional a partir do processo de redemocratização do país e da Constituição de 1988. A Carta Magna assumiu a qualidade de marco jurídico da transição democrática e da institucionalização dos direitos humanos (PIOVESAN, 2006).

No âmbito constitucional, os direitos humanos encontram-se assegurados. Enquanto pauta da agenda governamental, ganharam projeção com a criação do plano nacional dos 
direitos humanos (PNDH), em 1996. O PNDH teve três edições, todas elas sob a orientação de assegurar a criação e a consolidação de políticas públicas em direitos humanos (ADORNO, 2010). No que compreende a afirmação da liberdade religiosa, as três versões do PNDH reiteram a importância da liberdade de culto e de crença e o combate à intolerância religiosa. Em sua última versão, em 2009, houve uma maior preocupação com a dimensão da diversidade religiosa, que foi inserida como um dos eixos temáticos do programa, sendo criado, em 2014, o Comitê Nacional de Respeito à Diversidade Religiosa (CNRDR).

Na construção da agenda de políticas públicas voltada para a questão religiosa, os atores governamentais evocam os direitos humanos como referenciais para suas tomadas de decisão e como garantia da laicidade estatal ${ }^{1}$. Os atores não governamentais também incorporam os direitos humanos como base para as reivindicações de suas demandas. Para esses últimos, como defende Santos (2014), os direitos humanos se tornam uma semântica de dignidade humana, afirmando-se como uma concepção contra-hegemônica nas lutas por emancipação social.

Em síntese, a questão da diversidade religiosa ascendeu no campo político brasileiro, ganhando destaque na formulação das políticas públicas. Ela também teve representatividade como discurso político, tanto em defesa da liberdade religiosa como no combate à intolerância religiosa. Nesse contexto, cumpre investigar o discurso norteador do CNRDR a fim de compreender suas implicações e contribuições na relação entre religião e espaço público no Brasil.

\section{Embates e interlocuções: a intolerância religiosa e criação do CNRDR}

Segundo dados fornecidos pela Secretaria de Direitos Humanos da Presidência da República (SDH/PR), entre os anos de 2011 e 2015, foram registrados, em média, a cada três dias, uma denúncia de intolerância religiosa recebida pelo Disque 100, serviço destinado a receber as denúncias relativas à violação dos direitos humanos (SANT'ANNA, 2015). O acolhimento dessas denúncias acontece desde 2011, sendo reportado, no ano 2015, o maior

\footnotetext{
${ }^{1} \mathrm{Na}$ Declaração Universal dos Direitos Humanos, a questão religiosa aparece defendida no artigo 18 do documento da seguinte forma: "Todas as pessoas têm direito à liberdade de pensamento, de consciência e de religião; este direito implica a liberdade de mudar de religião ou de credo, assim como a liberdade de manifestar a sua religião ou credo, sozinho ou em comunidade com outros, quer em público ou em privado, através do ensino, prática, culto e rituais" (ONU, 1948, p. 10).
} 
número de casos registrados, 556, o que corresponde a um aumento de $273 \%$ em relação a 2014, quando foram feitas 149 denúncias. No quadro a seguir, é possível observar esquematicamente esses dados:

\begin{tabular}{|l|l|}
\hline \multicolumn{2}{|c|}{ Denúncias sobre casos de intolerância religiosa registrados de 2011 a $201 \mathbf{5}^{\mathbf{2}}$} \\
\hline 2011 & 15 queixas \\
\hline 2012 & 103 queixas \\
\hline 2013 & 231 queixas \\
\hline 2014 & 149 queixas \\
\hline 2015 & 556 queixas \\
\hline
\end{tabular}

Fonte: Souza (2017, p. 17)

Nesse contexto, cumpre conceituar o que seja a intolerância religiosa. Ela figura-se como uma violação ao direito à liberdade, posto que ela se caracteriza como: "um conjunto de ideologias e atitudes ofensivas, discriminatórias e de desrespeito às diferentes crenças e práticas religiosas ou a quem não segue uma religião" (SDH/PR, 2013, p. 9). Em razão disso, ela fere o princípio de liberdade religiosa tal como é assegurado no artigo $5^{\circ}$, inciso $\mathrm{VI}$ da Constituição Federal: "É inviolável a liberdade de consciência e de crença, sendo assegurado o livre exercício dos cultos religiosos e garantida, na forma da lei, a proteção aos locais de cultos e suas liturgias" (BRASIL, 1988).

A fim de responder à demanda social por políticas de combate à intolerância religiosa e garantia da liberdade religiosa, surge, em 2014, no âmbito da SDH/PR, o Comitê Nacional de Respeito à Diversidade Religiosa (CNRDR).

O CNRDR foi criado com o intuito de auxiliar a SDH/PR na elaboração de políticas para a liberdade e diversidade religiosa e the conferir caráter participativo, conforme Programa Nacional de Direitos Humanos III (PNDH-3). São estabelecidos pelo artigo ${ }^{\circ}{ }^{\circ}$, da Portaria no 18, de janeiro de 2014, como os objetivos do comitê:

I - promover o reconhecimento da diversidade religiosa do país e defender à liberdade religiosa e o direito a liberdade de crença e convicção;

\footnotetext{
${ }^{2}$ Quadro adaptado de Amorim (2016).
} 
II - auxiliar e propor iniciativas, ações e políticas de enfrentamento à intolerância por motivo de crença ou convicção;

III - contribuir no estabelecimento de estratégias de respeito à diversidade e liberdade religiosa e do direito de não ter religião, da laicidade do estado e do enfrentamento à intolerância religiosa3 (BRASIL, 2014, p. 3).

Dessa forma, o CNRDR assume o papel de aproximação entre as demandas sociais de tolerância religiosa e de políticas públicas. O CNRDR se constitui como uma tentativa de resposta ao problema da intolerância religiosa, comprometendo-se politicamente com valores que se articulam sobre a relação entre direitos humanos e diversidade religiosa. Caucionado por essa temática, o colegiado se delineia na especificidade do combate à intolerância religiosa e à promoção da diversidade religiosa. Nesse sentido, é possível afirmar que a perspectiva política na qual o CNRDR se assenta é a de uma visão contra-hegemônica dos direitos humanos. Esse conceito será mais bem detalhado na próxima seção.

\section{Interlocuções: a concepção contra-hegemônica dos direitos humanos}

Independentemente de quão antigos sejam os seus antecedentes históricos, os direitos humanos, como linguagem política de emancipação social, só entraram nas agendas nacionais e internacionais a partir das décadas de 1970 e 1980 (SANTOS, 2014). Nesse período, entraram em pauta o direito das coletividades, a defesa ao meio ambiente, o desenvolvimento, a autodeterminação dos povos e a partilha do patrimônio técnicocientífico e cultural4.

Analisando os fundamentos e o alcance dos direitos humanos, Santos (2014) argumenta que quatro ilusões compõem o senso comum sobre os direitos humanos: a teleologia, o triunfalismo, a descontextualização e o monolitismo.

\footnotetext{
3 Uma Portaria anterior, a nº 18 de Janeiro 2013, instituiu uma primeira versão do comitê, porém foi substituída pela Portaria $\mathrm{n}^{\circ} 18$, de Janeiro de 2014.

4 Para Santos (2014), os direitos humanos possuem pelo menos duas matrizes interpretativas que se desenvolveram no Ocidente, a de tradição liberal e a de tradição marxista: "A matriz liberal concebe os direitos humanos como direitos individuais e privilegia os direitos civis e políticos. Sobre esta matriz desenvolveram-se outras concepções de direitos humanos, nomeadamente as de inspiração marxista ou socialista, que reconhecem os direitos coletivos e privilegiam os direitos econômicos e sociais" (SANTOS, 2014, p. 16).
} 
A teleologia consiste em ler a história como um percurso linear que conduziu a um consenso sobre os direitos humanos e o bem incondicional que esse entendimento significou, gerando com isso um anacronismo acerca desses direitos:

Esta ilusão impede-nos de ver que, tal como no passado, é contingente, que, em cada momento histórico, diferentes ideias estiveram em competição e que a vitória de uma delas, no caso, os direitos humanos, é um resultado contingente que pode ser explicado a posteriori, mas que não poderia ser deterministicamente previsto (SANTOS, 2014, p. 18).

O triunfalismo corresponde à perspectiva de que a vitória dos direitos humanos é um bem incondicional da humanidade. Essa noção tem como pressuposto que outras semânticas de dignidade humana que concorreram com os direitos humanos e que não os invocaram para justificar as suas causas e as suas lutas eram eticamente ou politicamente inferiores (SANTOS, 2014). São exemplos dessa semântica os movimentos de libertação anticoloniais do século XX e os movimentos socialista e comunista.

O fato de outras gramáticas e linguagens de emancipação social terem sido derrotadas pelos direitos humanos só poderá ser considerado inerentemente positivo se se mostrar que os direitos humanos tem um mérito, enquanto linguagem de emancipação humana, que não se deduz apenas do fato de terem saído vencedores. Até que tal seja mostrado, o triunfo dos direitos humanos pode ser considerado, para uns, um progresso, uma vitória histórica, e, para outros, um retrocesso, uma derrota histórica (SANTOS, 2014, p. 19).

A descontextualização consiste em não considerar que os direitos humanos foram usados em contextos muito distintos e com objetivos controversos como discurso e arma política, inclusive para legitimar práticas de violação dos seus próprios preceitos:

Quando, a partir do de meados do século XIX, o discurso dos direitos humanos se separou da tradição revolucionária, passou a ser concebido como uma gramática despolitizada de transformação social, uma espécie de antipolítica. Os direitos humanos foram subsumidos no direito do Estado, e o Estado assumiu o monopólio da produção do direito e de administração da justiça (SANTOS, 2014, p. 21).

O monolitismo fundamenta-se na negação das tensões e contradições internas nas teorias dos direitos humanos. Isso porque cultivam uma ambiguidade com os direitos do cidadão. Os direitos humanos se referem a uma coletividade mais inclusiva, a humanidade, ao passo que os direitos do cidadão remetem à coletividade dos cidadãos de um determinado 
Estado (SANTOS, 2014). Os direitos humanos são geralmente evocados quando há alguma violação grave dos direitos de cidadania:

Os direitos humanos surgem como o patamar mais baixo de inclusão, um movimento descendente da comunidade mais densa de cidadãos para a comunidade mais diluída de humanidade. Com o neoliberalismo e o seu ataque ao Estado como garante dos direitos, em especial os direitos econômicos e sócias, a comunidade dos cidadãos dilui-se ao ponto de se tornar indistinguivel da comunidade humana e dos direitos de cidadania, tão trivializados com os direitos humanos (SANTOS, 2014, p. 22-23).

Outro conflito que ilustra a ilusão do monolitismo é a tensão entre os direitos individuais e coletivos. A Declaração Universal dos Direitos Humanos só reconhece dois tipos de sujeitos jurídicos: o indivíduo e o Estado. As coletividades, isto é, povos, nações, etc., que não possuíam Estado estavam ausentes na concepção original do documento. Ficaram de fora da pauta dos direitos humanos as questões relativas à dominação coletiva, para as quais os direitos individuais não ofereciam proteção. Só a partir dos meados dos anos de 1960 as lutas anticoloniais entram na agenda das Nações Unidas:

As lutas das mulheres, dos povos indígenas, afrodescendentes, vítimas do racismo, gays, lésbicas e minorias religiosas marcam os últimos cinquenta anos de reconhecimento dos direitos coletivos, um reconhecimento sempre amplamente contestado e em constante risco de reversão (SANTOS, 2014, p. 25).

A partir dessa crítica, Santos (2014) propõe a concepção contra-hegemônica dos direitos humanos. Nesse sentido, cabe apresentar a distinção feita por Santos (2014) entre hegemônico e contra-hegemônico. Para o autor, essa diferenciação só pode ser determinada contextualmente:

Como a concebo aqui, a hegemonia é um feixe de esquemas intelectuais e políticos que são vistos pela maioria das pessoas (mesmo por muitos dos que são negativamente afetados por ela) como fornecendo o entendimento natural ou único possível da vida social. Por outro lado, a contra-hegemonia resulta de um trabalho organizado de mobilização intelectual e política contra a corrente, destinado a desacreditar os esquemas hegemônicos e fornecer entendimentos alternativos credíveis da vida social (SANTOS, 2014, p. 33).

Por esse viés, os direitos humanos são compreendidos como uma noção intercultural e que deve estar em diálogo com outras noções de dignidade humana, contrapondo-se à 
perspectiva hegemônica dos direitos humanos que os concebem como: "individualistas, seculares, culturalmente ocidente-cêntricos, e Estado-cêntricos, quer quando visam controlar o Estado, quer quando pretendem tirar proveito dele" (SANTOS, 2014, p. 11).

Nesse sentido, Santos (2014) advoga que as teologias pluralistas e progressistas podem exercer um importante papel na consolidação de uma cultura contra-hegemônica dos direitos humanos, uma vez que elas têm assumido uma postura de oposição à noção preponderante, submetendo esses direitos a um processo de reconstrução política e filosófica5:

[...] os ativistas da luta por justiça socioeconômica, histórica, sexual, racial, cultural e pós-colonial baseiam frequentemente o seu ativismo e as suas reivindicações em crenças religiosas ou espiritualidades cristãs, islâmicas, hindus, budistas e indígenas. De certo modo, estas posições dão testemunho de subjetividades políticas que parecem ter abandonado o pensamento crítico ocidental e a ação política secular que dele decorre. Tais subjetividades combinam efervescência criativa e energia apaixonada e intensa com referências transcendentes ou espirituais que, longe de as afastarem das lutas materiais e bem terrenas por um mundo possível, mais profundamente as comprometem com estas (SANTOS, 2014, p. 12-13).

A distinção entre os espaços público e privado é posta em questão por esses grupos, assim como o confinamento da religião à esfera particular. Elemento central no imaginário político ocidental, essa separação ocultaria relações de opressão tanto no plano da regulação social como na da emancipação social. Assim, a reivindicação da religião como elemento constitutivo da vida pública tem ganhado projeção nas lutas por justiça social em nível global $^{6}$, como afirma Santos (2014):

Trata-se de um fenômeno multifacetado, tanto no que respeita às denominações envolvidas como no tocante às orientações políticas e culturais. Mas sua presença é marcante em todo mundo e as redes que a alimentam são transnacionais, o que nos permite nomeá-las como fenômeno global (SANTOS, 2014, p. 37).

\footnotetext{
5 Sob um viés teológico, Ribeiro (2016) desenvolve um estudo sobre os impactos da presença pública interreligiosa na promoção da democracia e dos direitos humanos. Todavia a argumentação se desenvolve mais por uma perspectiva ecumênica de diálogo do que pela proposta contra-hegemônica dos direitos humanos de Santos (2014).

${ }^{6}$ No caso brasileiro, esse fenômeno pode ser observado a partir dos anos de 1990 com a inserção da religião no domínio das políticas sociais, em especial nas iniciativas de combate à pobreza e promoção da cidadania (BURITY, 2006).
} 
Em síntese, os direitos humanos concebidos criticamente e sob o viés contrahegemônico possibilitam uma abertura para a dimensão religiosa a fim de contribuir para a tradução de outras lógicas interculturais e a abertura para o diálogo com outras semânticas de dignidade humana, sejam elas religiosas ou não. Assim, a compreensão e alcance dos direitos humanos se ampliam para além da dimensão sociocultural em que se originaram e trazem para o centro da sua pauta a importância do entendimento da diversidade e pluralidade religiosa nos processos de emancipação social. A dimensão religiosa, que, em um dado momento histórico, foi concebida como um empecilho para a garantia das liberdades civis nas repúblicas modernas faz um movimento reverso, passando a integrar os movimentos de luta pela efetivação dos valores democráticos.

\section{Um olhar a partir da Análise do Discurso}

Na pesquisa, foi proposto o seguinte movimento: trabalhar a perspectiva teóricometodológica da Análise do discurso (doravante AD) no interior do campo (inter)disciplinar das Ciências da Religião (CR). Em CR, é possível que as disciplinas tenham a sua autonomia teórico-metodológica, desde que elas mantenham um interesse comum pelo tema religião (CAMURÇA, 2008). Sob esse viés, a inserção da $A D$ no campo das $C R$ se torna possível, uma vez que ela também tem como objeto de suas análises o discurso religioso (ORLANDI, 1996) e as relações discursivas entre religião e política (COURTINE, 2009).

Nesse sentido, a articulação proposta, atrelando a perspectiva da análise dos processos discursivos ao tema religião, também pode pôr em questão a própria via que lhe deu acesso às $C R$. Ao trabalhar os princípios teóricos da $A D$ no interior das $C R$, tem-se muito mais do que a construção do objeto e o estabelecimento dos seus procedimentos analíticos para uma única pesquisa: abre-se espaço para o questionamento do estatuto epistemológico das $C R$, uma vez que a $A D$ também se ocupa em estudar os discursos científicos. Para a $A D$, o discurso, sob a aparência de transparência da linguagem, oculta que o seu sentido é sempre dividido, e que essa divisão não é indiferente às injunções das relações de força provenientes das formações sociais em uma dada conjuntura histórica. Dito de outro modo: o sentido de um discurso não existe em si mesmo, como um dado a priori, todavia inscreve-se em posições ideológicas que estão em concorrência no processo sócio-histórico em que ele é produzido. 
Cabe fazer uma importante demarcação teórica para a AD: o conceito de ideologia. Ela não é compreendida como visão de mundo ou ocultação da realidade, mas como modo de funcionamento estruturante da relação entre linguagem e mundo no processo de significação (ORLANDI, 2001). A ideologia fornece as evidências do caráter material do sentido à medida que faz com que uma palavra ou enunciado queiram dizer o que realmente dizem e ocultam, sob a impressão de transparência da linguagem, a materialidade do sentido das palavras e dos enunciados (PÊCHEUX, 2014). Desse modo, um discurso não possui um sentido em si mesmo, mas ele é produzido por meio de posições ideológicas que estão em concorrência no processo sócio-histórico em que ele é produzido:

[...] as palavras, expressões, proposições, etc., mudam de sentido segundo as posições sustentadas por aqueles que as empregam, o que quer dizer que elas adquirem seu sentido em referência a essas posições, isto é, em referência às formações ideológicas (PÊCHEUX, 2014, p. 146-147).

Assim, a questão do sentido é uma questão aberta, pois ele sempre está em curso. A despeito disso, não é porque ele é aberto que o processo de significação não é administrado: "A ideologia, por sua vez, é interpretação de sentido em certa direção, direção determinada pela relação da linguagem com a história em seus mecanismos imaginários" (ORLANDI, 2004). Sob esse viés, o discurso é uma noção que possibilita pensar as relações de mediação do homem com o mundo por meio da linguagem. Em síntese, o discurso é uma das instâncias concretas da relação linguagem-pensamento-mundo.

Dois conceitos operativos que emergem do quadro teórico da AD foram de caráter substancial para a pesquisa empreendida7: os conceitos de formação discursiva (FD) e de formação ideológica (FI).

A formação ideológica se caracteriza como um elemento possível de intervir em uma formação social como uma força em confronto com outras forças em uma conjuntura ideológica específica:

[...] cada formação ideológica constitui um conjunto complexo de atitudes e de representações que não são nem "individuais" nem "universais" mas se relacionam mais ou menos diretamente a posições de classes em conflito umas com as outras (PÊCHEUX; FUCHS, 1997, p. 166).

\footnotetext{
7 Vale acrescentar que outros conceitos não expostos aqui, como os de pré-construído, posição-sujeito, interdiscurso, etc., também foram utilizados na pesquisa. Apesar disso, os conceitos basilares foram os FD e $\mathrm{Fl}$.
} 
Assim, uma Fl comporta como um dos seus elementos uma ou mais formações discursivas interligadas que regulam o que pode e deve ser dito em uma dada conjuntura ideológica. Em razão disso, todos os dizeres do sujeito estão inseridos em uma formação discursiva (FD). A FD será conceituada por Pêcheux (2014) como:

[...] aquilo que, numa formação ideológica dada, isto é, a partir de uma posição dada numa conjuntura dada, determinada pelo estado da luta de classes, determina o que pode e deve ser dito (articulado sob a forma de uma arenga, de um sermão, de um panfleto, de uma exposição, de um programa, etc.) (PÊCHEUX, 2014, p.147).

Desse modo, a FD é entendida como o lugar de constituição do sentido, posto que, por meio dela, os indivíduos são interpelados em sujeito do seu discurso, e ela exprime, na linguagem, as Fls que Ihe são correspondentes (PÊCHEUX, 2014). As FDs intervêm nas Fls como elementos capazes de materializar a contradição entre diferentes posições ideológicas, uma vez que: "É no interior de uma FD que se realiza o 'assujeitamento' do sujeito (ideológico) do discurso" (COURTINE, 2009, p. 73). O espaço de uma FD é atravessado por elementos préconstruídos, isto é, discursos que vieram de uma construção anterior e exterior e que correspondem: "ao 'sempre-já-ai' da interpelação ideológica que fornece-impõe a 'realidade' e seu 'sentido' sob a forma de universalidade" (PÊCHEUX, 2014, p. 151).

\section{O discurso político do CNRDR em foco: análise e discussão de dados}

A partir da base teórico-metodológica da $A D$, estabeleceu-se o procedimento analítico da pesquisa. Por intermédio dos conceitos dessa disciplina, estabeleceu-se o gesto de leitura sobre o corpus analisado, sendo objeto de análise as atas e notas públicas da primeira gestão do CNRDR.

A escolha do CNRDR, representado por meio do discurso político do seu colegiado, deu-se em função das seguintes motivações: 1) a relevância social do comitê, uma vez que a sua criação representa a inserção da dimensão religiosa na agenda governamental sobre políticas públicas em direitos humanos no Brasil; 2) ao fato de que o CNRDR desponta como uma possibilidade efetiva de escuta de membros da sociedade civil e também como uma possibilidade de participarem do processo de elaboração de políticas públicas para a diversidade religiosa. 


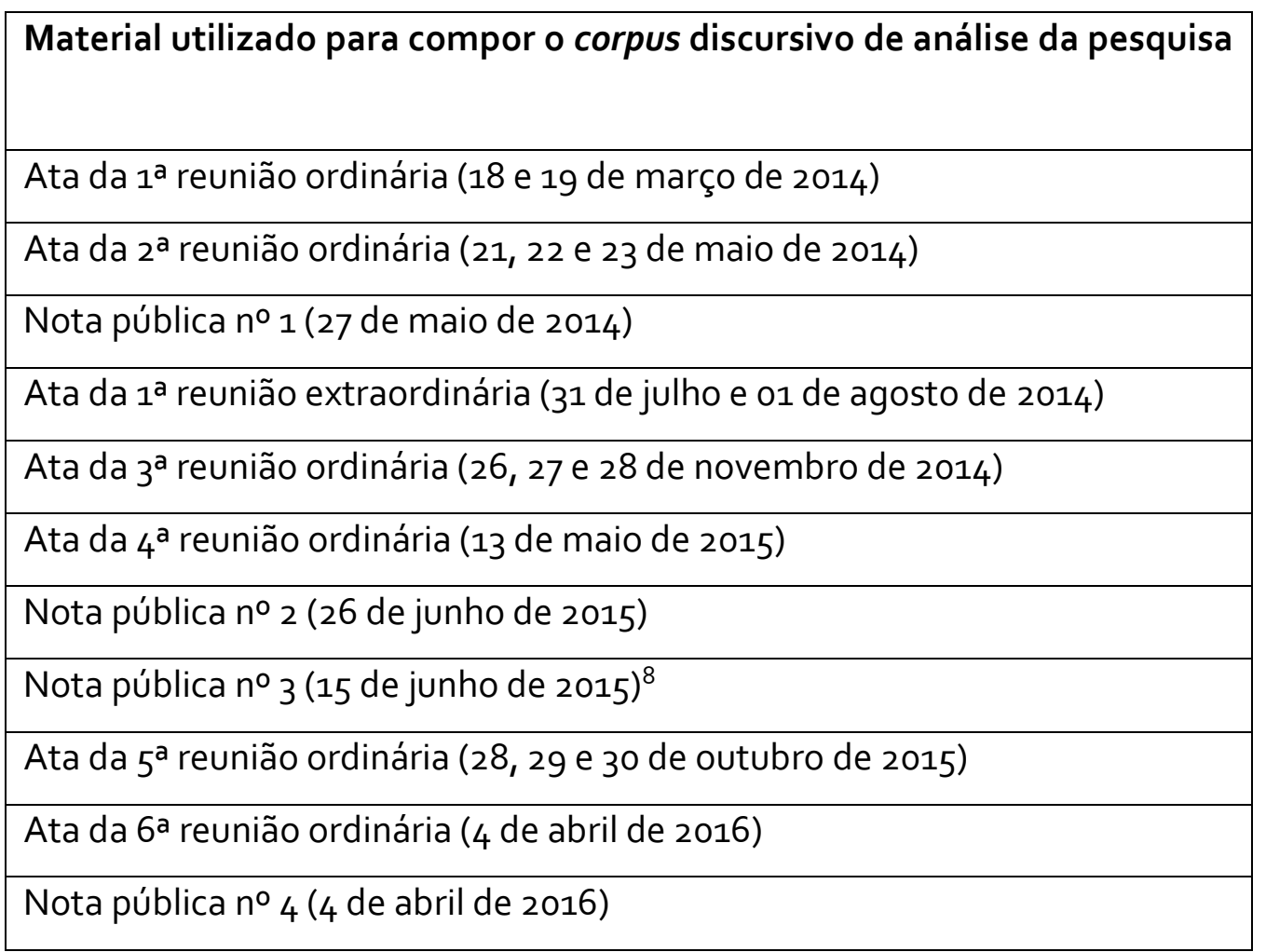

Fonte: Souza (2017, p. 58)

Os principais critérios discursivos utilizados para o trabalho feito no corpus, constituído de vinte e sete sequências discursivas ${ }^{9}$ selecionadas, foram os de formação discursiva (FD) e formação ideológica (FI). Essas sequências foram indicadas em negrito antes de sua apresentação e enumeradas cronologicamente. As marcações nas sequências foram feitas em itálico, sendo, em seguida, apresentas as suas respectivas análises. Ao início da análise de cada ata e nota pública, foi realizada uma descrição da conjuntura sócio-histórica das condições de produção que marcaram as suas elaborações.

A fim de exemplificar o procedimento analítico adotado, será apresentada a seguir a análise de uma das sequências discursivas selecionadas da ata da primeira reunião ordinária do CNRDR:

\footnotetext{
8 Apesar da nota pública $\mathrm{n}^{\circ} 3$ ter sido publicada antes da $\mathrm{n}^{\circ}{ }_{2}$, optou-se por mantê-las da forma como foram classificadas pelo CNRDR.

9 As sequências discursivas são conceituadas por Courtine (2009, p. 55) como: "sequências orais ou escritas com dimensão superior à frase". Apesar disso, o autor considera que essa noção é flexível, tendo em vista que a forma e natureza das sequências discursivas podem variar, a depender do tipo de abordagem que elas serão submetidas em cada análise.
} 
Sequência discursiva

5) Campanhas pelo respeito à diversidade religiosa: promover e apoiar eventos temáticos relacionados à diversidade religiosa e à laicidade do estado para o fortalecimento da liberdade, da igualdade e da democracia religiosa; utilização de mídias, spots, entre outros produtos midiáticos (CNRDR, 2014a, p. 3, grifos nossos).

Um gesto de leitura para esse fato seria o de que o discurso do CNRDR é decorrente de uma formação discursiva enunciada a partir de um lugar ideológico que valoriza a relação entre direitos humanos e diversidade religiosa. Essa FD será denominada de formação discursiva em direitos humanos e diversidade religiosa (doravante FD[dhdr] ). A demarcação dessa FD na sequência analisada, tem por objetivo fornecer um aspecto dominante no corpus discursivo e, a partir dele, reconstituir o processo discursivo inerente à FD que o domina (COURTINE, 2009). A FD(dhdr) cauciona o modo como a diversidade religiosa é concebida pelo comitê, isto é, legitimada no campo das políticas públicas como um valor pertencente aos direitos humanos. Isso porque a defesa dos direitos humanos se constitui como um compromisso político do Estado, por meio da emenda constitucional no 45/2004 que estabelece que os tratados e convenções internacionais sobre direitos humanos aprovados em cada Casa do Congresso Nacional serão equivalentes às emendas à Constituição. Dessa forma, os direitos humanos adquirem o status de norma constitucional (PIOVESAN, 2006). Assim, essa FD dominante funciona como a matriz de sentido para as diferentes temáticas de que o CNRDR se ocupará como, por exemplo, o ensino religioso e projetos de lei que versam sobre a liberdade religiosa no país (SOUZA, 2017).

Por meio das análises ${ }^{10}$, observaram-se os seguintes aspectos no discurso do CNRDR: 1) sob a impressão de transparência da linguagem, os sentidos do político estão sempre divididos do discurso do CNRDR. Há uma dinâmica contraditória e complementar às noções de direitos humanos e de diversidade religiosa; 2 ) a articulação temática desenvolvida pelo CNRDR se constitui por um conflito entre formações ideológicas no interior de uma formação discursiva dominante, a FD(dhdr). Ela cauciona o modo como a diversidade religiosa é concebida pelo comitê, isto é, legitimada no campo das políticas públicas como um valor

\footnotetext{
${ }^{10}$ Em função dos limites desse artigo, não poderei expor toda a composição do procedimento analítico da pesquisa. Remeto o leitor ao texto de Souza e Aragão (2017). Nele, os autores elucidam com maiores detalhes a construção do procedimento desenvolvido. Para um maior aprofundamento da questão, conferir (SOUZA, 2017).
} 
pertencente aos direitos humanos; 3) no interior dessa FD, há o embate entre duas formações ideológicas: a Fl da diferença e a FI da unidade. Essas instâncias remetem à relação ideológica entre democracia e república no âmbito da política. Na Fl da diferença, privilegia-se a individualidade como fator primordial para constituição dos sentidos da política, já na FI da unidade, tem-se o coletivo como elemento fundador dos sentidos na política. Essas Fls estabelecem entre si uma relação de conflito e aliança, uma vez que articulam e estruturam no interior da FD(dhdr) os direitos humanos, que possuem uma perspectiva universalista da noção de direitos, e a concepção de diversidade religiosa, que prima pela individualidade e pelas diferenças religiosas e culturais

No que se refere à conjuntura histórico-política em que CNRDR está situado, foram observados os seguintes pontos: 1) que a criação e o desenvolvimento do CNRDR ocorre paralelamente a um forte período de instabilidade política e econômica (2013-2016); 2) as diferentes mudanças de gestão no CNRDR e na SDH/PR reverberam a fragilidade do governo frente às crises política e econômica enfrentadas; 3) o destaque para a diversidade religiosa e temáticas relacionadas acontecem durante a gestão petista da Presidência da República; 4) a dupla dificuldade do comitê em definir um conceito de religião e de diversidade religiosa. Sob esse último aspecto, algumas observações precisam ser feitas.

O não aprofundamento do CNRDR da noção de diversidade religiosa reflete uma carência de parâmetros para o assessoramento da SDH/PR na elaboração de políticas públicas que contemplem a promoção da liberdade religiosa e do combate à intolerância religiosa. Essa indefinição dificulta o próprio funcionamento do CNRDR como também o desenvolvimento de critérios para a sua prática política.

Tomando esse problema como ponto de partida, Souza e Aragão (2017) defendem que a diversidade religiosa pode intervir como um conceito para compreender os embates ideológicos que ocorrem em torno da relação entre religião e política no espaço público. Para isso, os autores propõem que ela deve ser pensada a partir do funcionamento discursivo dessa relação:

Assim, a diversidade religiosa pode ser compreendida como uma posiçãosujeito que faz reverberar a luta ideológica pela valorização da diversidade de crenças no espaço público. Nela, inscreve-se a reivindicação da religião como elemento constitutivo da vida pública, pondo em questão o confinamento da religião à esfera particular. No discurso, ela é o local a ser ocupado na disputa por políticas públicas que protejam a pluralidade das religiões e que combatam a intolerância religiosa, marcando um lugar de 
confronto, de disputa por significação na política (SOUZA; ARAGÃO, 2017, p. 75).

Nesse contexto, a diversidade religiosa pode ser compreendida como um parâmetro analítico que possibilita tanto para as pesquisas em CR como em $A D$ o entendimento das relações de força que se estabelecem no espaço público brasileiro e que reivindicam a religião como um aspecto constituinte da democracia e da vida pública. Como local de disputa por políticas públicas, a diversidade religiosa se filia a uma concepção contra-hegemônica dos direitos humanos, tal como apontada por Santos (2014), trazendo para o centro da sua pauta a importância do entendimento da diversidade e pluralidade religiosa nos processos de emancipação social.

Dessa forma, a diversidade religiosa, enquanto posição-sujeito (SOUZA; ARAGÃO, 2017), marcaria uma oposição ao entendimento produzido na modernidade da distinção entre o espaço público e privado, assim como o confinamento da religião à esfera particular. Assim, a diversidade religiosa consistiria nesse espaço discursivo em que estão entrelaçadas a religião e as lutas por justiça social.

\section{Considerações finais}

Neste artigo, apresentamos uma síntese do trabalho desenvolvido na nossa dissertação de mestrado assim como seus desdobramentos. Num primeiro momento, situou-se a questão da intolerância religiosa no Brasil e os casos de denúncias feitas ao Disque 100 e o surgimento do CNRDR como uma resposta à demanda social por políticas de combate à intolerância religiosa e promoção da liberdade religiosa. Em um segundo momento, expôsse a perspectiva contra-hegemônica dos direitos humanos proposta por Santos (2014). O autor defende que essa perspectiva torna possível a inserção da dimensão religiosa no espaço dos direitos humanos assim como a articula nas lutas por emancipação social. Em um terceiro momento, apresentou-se o quadro teórico metodológico da pesquisa, a AD. Por meio de uma rápida exposição, elucidaram-se alguns dos seus principais conceitos e o objeto da disciplina, isto é, o discurso. Por último, apresentaram-se os resultados de análise da pesquisa e os seus desdobramentos através de uma resignificação pelo viés discursivo da noção de diversidade religiosa. 
Esperamos, por meio deste artigo, ter despertado o interesse do leitor para se aprofundar nas questões sobre religião e espaço público como também mostrar como a Análise do Discurso pode ser uma ferramenta útil aos estudos de religião, possibilitando uma nova abordagem nesse campo de pesquisa.

\section{Referências}

ADORNO, Sérgio. História e desventura: $03^{\circ}$ Programa Nacional de Direitos Humanos. Novos estudos CEBRAP, São Paulo, n.86, p. 5-20, mar. 2010. Disponível em: $<w w w . s c i e l o . b r / p d f / n e c / n 86 / n 86 a 01 . p d f>$. Acesso em: 12/10/2015.

AMORIM, Felipe. No de denúncias de intolerância religiosa no Disque 100 é maior desde 2011. UOL Notícias, Brasília, 21 jan. 2016. Disponível em: <noticias.uol.com.br/cotidiano/ultimas-noticias/2016/01/21/n-de-denuncias-deintolerancia-religiosa-no-disque-100-e-maior-desde-2011.htm>. Acesso em: 16/02/2016.

BRASIL. Constituição (1988). Constituição da República Federativa do Brasil. Brasília, DF: Senado Federal: Centro Gráfico, 1988.

Diário Oficial [da] República Federativa do Brasil. Brasília, 31 jan. 2014. Seção 1, p.

3.

BURITY, Joanildo A. Redes, parcerias e participação religiosa nas políticas sociais no Brasil. Recife: Fundação Joaquim Nabuco, Ed. Massangana, 2006.

CAMURÇA, Marcelo. Ciências Sociais e Ciências da Religião: polêmicas e interlocuções. São Paulo: Paulinas, 2008.

COMITÊ NACIONAL DE RESPEITO À DIVERSIDADE RELIGIOSA. Ata da primeira reunião ordinária do Comitê Nacional de Respeito à Diversidade Religiosa - CNRDR/SDH/PR. Secretaria de Direitos Humanos da Presidência da República. Brasília, 18-19 mar. 2014. Disponível em: <www.sdh.gov.br/sobre/participacao-social/cnrdr/pdfs/ata-1a-ro-cnrdr-19de-marco-de-2014>. Acesso em: 03/05/2015.

COURTINE, Jean-Jacques. Análise do discurso político: o discurso comunista endereçado aos cristãos. São Carlos: EdUFSCar, 2009.

ORGANIZAÇÃO MUNDIAL DAS NAÇÕES UNIDAS. Declaração Universal dos Direitos Humanos, 1948. Disponível em: <www.dudh.org.br/wpcontent/uploads/2014/12/dudh.pdf>. Acesso em: 29/05/2016.

ORLANDI, Eni P. A linguagem e seu funcionamento: as formas do discurso. Campinas: Pontes, 1996.

. Análise de discurso: princípios e procedimentos. Campinas: Pontes, 2001. 
Interpretação: autoria, leitura e efeitos do trabalho simbólico. Campinas: Pontes, 2004 .

PÊCHEUX, Michel.; FUCHS, Catherine. A propósito da análise automática do discurso: atualização e perspectivas (1975). In: GADET, F; HAK, T. (Org.). Por uma análise automática do discurso: uma introdução à obra de Michel Pêcheux. Campinas: Editora da UNICAMP, 1997. p. 163-252.

PÊCHEUX, Michel. Semântica e discurso: uma crítica à afirmação do óbvio. Campinas: Editora da UNICAMP, 2014.

PIOVESAN, Flávia. Direitos humanos e direito constitucional internacional. Caderno de direito constitucional. Escola de magistratura do Tribunal Regional Federal da $4^{\text {a região, }}$ 2006.

SANT'ANNA. Emílio. A cada 3 dias o governo recebe uma denúncia de intolerância religiosa. Folha de São Paulo, São Paulo, 27 jun. 2016. Disponível em: $<$ <ww1.folha.uol.com.br/cotidiano/2015/06/1648607-a-cada-3-dias-governo-recebe-umadenuncia-de-intolerancia-religiosa.shtml>.

SANTOS, Boaventura de Sousa. Se Deus fosse um ativista dos direitos humanos. São Paulo: Cortez, 2014.

\section{SECRETARIA DE DIREITOS HUMANOS DA PRESIDÊNCIA DA REPÚBLICA. Diversidade} religiosa e direitos humanos. Brasília: Editora União Planetária, 2013.

SOUZA, Mailson Fernandes Cabral. Religião e espaço público: o discurso político do Comitê Nacional de Respeito à Diversidade Religiosa. 104p. [Dissertação de mestrado em Ciências da Religião]. Universidade Católica de Pernambuco, 2017.

SOUZA, Mailson Fernandes Cabral; ARAGÃO, Gilbraz Souza. Se não cabe ao Estado definir um conceito de religião, o que é um crime de intolerância religiosa? Uma análise discursiva. In: SILVA, D. S.; SILVA, F. V. (Org.). Pêcheux e Foucault: caminhos cruzados na Análise do Discurso. São Carlos: Pedro \& João Editores, 2017, v. , p. 61-78. Disponível em: $<$ https://drive.google.com/file/d/oBoDneSsHmlj-ZEQ5MXVTODItNXc/view>. Acesso em 18/05/2017.

\section{Abstract}

This paper aim to present a brief itinerary of the relationship between human rights and religious diversity in Brazil, based on the analysis established in our master's research on the political discourse of the Comitê Nacional de Respeito à Diversidade Religiosa (CNRDR). In order to understand the relationship between religion and public space in the Brazilian scenario, the discourse of the CNRDR is taken as a point of observation, presenting some of its main aspects that were observed during the course of the research. Having as the theoreticalmethodological framework of the French Discourse Analysis, it was possible to perceive, in the discursive of the committee, that the relationship between human rights and religious diversity occurs through a dynamic of contradiction and complementarity, which brought To the 
evidence that the CNRDR does not have a concept of established religious diversity. Nevertheless, this heterogeneous and open notion allows the insertion of religion within the scope of public policies. Under this bias, religious diversity can represent a reading gesture for understanding the ideological conflicts that occur in the relationship between religion and politics in the Brazilian public space.

Keywords: Public Space. Religious Freedom. Religion and Discourse. 